\title{
The Contribution of Climate Change and Human Activities to the Sediment Discharge Changes of Xiangxi River Watershed in the Gorges Reservior Region
}

\author{
Changwei Zhang ${ }^{1, a}$, Xiaoying Pan ${ }^{1, b}$ and Wenbo $\mathrm{Xu}^{1, \mathrm{c}}$ \\ ${ }^{1}$ wuhan, hubei province jiangan district 23 Huangpu avenue, in china \\ achangweizhang0418@163.com, bpanxiaoying2010@126.com, cgdan125@126.com
}

\begin{abstract}
Keywords: sediment discharge; precipitation; human activities; contribution rate; Xiangxi River watershed

Abstract.Based on the meteorological and hydrological data collected from in Xiangxi River watershed during 1974 -2010, the mutation point of the sediment yield and precipitation were detected with the help of Pettitt test, accumulative anomaly analysis and double mass curve analysis . Meanwhile, the proportion of contribution of climate and human activities to the sediment yield change were researched by the method of slope change ratio of cumulative quantity. The result showed that the sediment yield change altered abruptly in 1978 and 1989 , annual precipitation in 1989,respectively ;Using the double accumulative curve based on rainfall VS sediment , the whole period was divided into three phases : 1974-1978 , 1979-1989 and 1989-2010; The contribution rates of the human intervention were 100\% during 1979-1989 and 155.35\% during 1990-2010, compared to that during 1974-1978 . The contribution rates of the human intervention were $79.11 \%$ during 1990-2010 compared to that during 1979-1989 . This research indicates the trend of sediment load change and rainfall in Xiangxi River watershed during 1974-2010, and also the contributions of precipitation and human activity. It is not only important to the soil and water conservation and assessment, but also provides theoretical support to the sharp decline of sediment discharge in Three Gorges Reservoir Area.
\end{abstract}

\section{Introduction}

Soil erosion is one of the major ecological problems of common concern to the world and also the primary environmental problems in china[1-3]. it is a very complicated system engineering to research soil erosion and sediment yield, it is not only controlled by natural factors and human activities, and the influence factors of erosion and sediment yield also exist the intricate interactions.

The tributary of the three gorges reservoir area is one of the important source of sediment and non-point source pollutants area, which has direct influence on reservoir sedimentation and water quality.the three gorges reservoir area is one of the four key soil and water conservation area in the upper Yangtze river valley, government has listed as the national focus on prevention and control of soil erosion area in the region Disturbance strongly, because of reservoir immigration and relocation of land in the basin are greatly influenced by human activities. Past research more concentrated in the basin of the river basin ecological water requirement, evaluation of river basin ecological health and safety, etc. are not covered by relation of river basin rainfall and sediment[4-7].

Therefore, further study of the three gorges reservoir area xiangxi watershed rainfall and sediment transport characteristics and driving factors change is contribute to the protection and prolong the service life of the reservoir . in order to deeply understand these problems, this study research the correlation analysis between the changes of precipitation and sediment from 1974 to 2010, and its contribution rate are analyzed. the result is not only to the area of soil and water loss management, but also provide certain theoretical support for the cause of the decline of rainfall and sediment yield. 


\section{2、Overview of the study area}

Xiangxi river is the type of the river valley, located in the upper Yangtze river area, originated in shennongjia the foothill, which is watershed area $3183 \mathrm{~km}^{2}$, in shennongjia forest region, including $865 \mathrm{~km}^{2}$, xingshan county $2106 \mathrm{~km}^{2}$, zigui county $212 \mathrm{~km}^{2}$. River basin climate belong to the sub-tropical continental monsoon climate zone. After the impoundment of the three gorges project, formed a typical xiangxi bay.Xiangxi river is Shortage of land resources, because of years of blind reclamation, deforestation, forest vegetation destroyed in the late 1980s, soil and rock bare due to a lot of sediment into the river.Remote sensing image show basin soil erosion area of $2244.72 \mathrm{~km}^{2}$ in 1988, accounting for $70.5 \%$ of the total area of the basin, which strongly and above degree of soil erosion area accounted for $25.97 \%$ of the basin area, $36.82 \%$ of the total area of soil and water loss [8].

\section{Date source and Method}

\subsection{Date source}

the data of this study come from xiangxi river xingshan county GaoYang Town xinshan hydrological station (2 kinds of national important precision stand), including sediment data of 1974-2010 in the xinshan hydrological station and within the scope of control for 1974-2010 precipitation station observation data by hydrological yearbook of the Yangtze river water resources commission compilation, the reliability and precision of data meet the computing requirements. The basic information of each site are shown in table 1. Xiangxi watershed water system diagram and weather station distribution is shown in Fig 1.

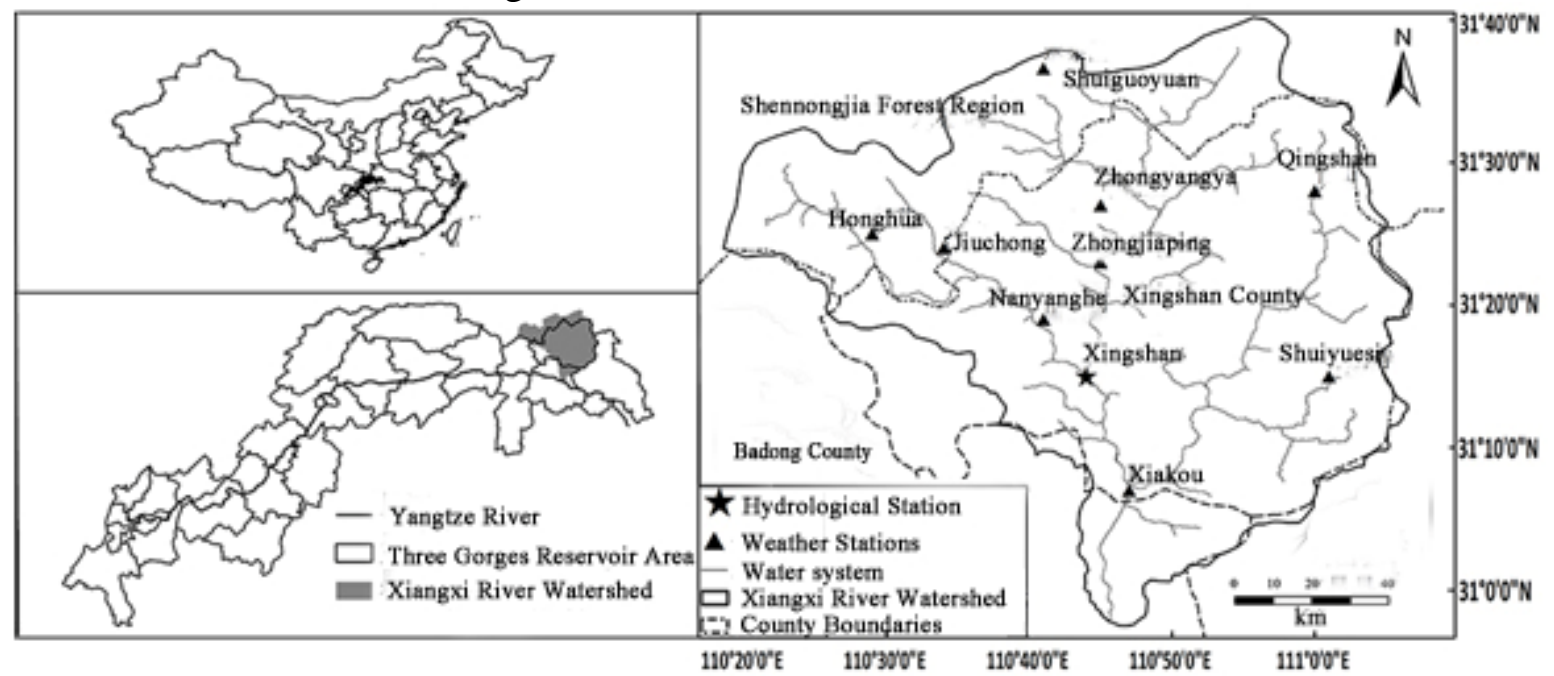

Fig.1 Location of weather station and hydrologic station in Xiangxi river

Tab.1 Basic information of weather station/hydrologic station characteristics in the Xiangxi River Watershed

\begin{tabular}{|c|c|c|c|c|c|c|}
\hline \multirow{2}{*}{ Rain gauges } & \multicolumn{3}{|c|}{ Location information } & \multicolumn{3}{|c|}{ Rainfall characteristics/mm } \\
\hline & longitude & Latitude & Elevation/m & Maximun & Minimun & Average \\
\hline Honghua & $110^{\circ} 29^{\prime}$ & $31^{\circ} 25^{\prime}$ & 823 & 1883.1 & 958.2 & 1256.8 \\
\hline Jiuchong & $110^{\circ} 34^{\prime}$ & $31^{\circ} 24^{\prime}$ & 684 & 1756.4 & 750.8 & 1254.8 \\
\hline Nanyanghe & $110^{\circ} 41^{\prime}$ & $31^{\circ} 19^{\prime}$ & 212 & 1969.9 & 834.3 & 1162.8 \\
\hline Shuiguoyuan & $110^{\circ} 41^{\prime}$ & $31^{\circ} 39^{\prime}$ & 1203 & 1672.7 & 747.9 & 1135.4 \\
\hline Zhongyangya & $110^{\circ} 45^{\prime}$ & $31^{\circ} 27^{\prime}$ & 1282 & 1561.3 & 885.5 & 1151.7 \\
\hline Qingshan & $110^{\circ} 53^{\prime}$ & $31^{\circ} 27^{\prime}$ & 1352 & 1460.2 & 796.4 & 1058.3 \\
\hline Zhengjiaping & $110^{\circ} 45^{\prime}$ & $31^{\circ} 23^{\prime}$ & 464 & 1332.5 & 660.1 & 939.9 \\
\hline Xingshan & $110^{\circ} 45^{\prime}$ & $31^{\circ} 15^{\prime}$ & 189 & 1449.6 & 726.5 & 996.8 \\
\hline Shuiyuesi & $110^{\circ} 01^{\prime}$ & $31^{\circ} 15^{\prime}$ & 865 & 1369.5 & 716.0 & 1038.2 \\
\hline
\end{tabular}




\begin{tabular}{lllllll}
\hline xiakou & $110^{\circ} 47^{\prime}$ & $31^{\circ} 07^{\prime}$ & 180 & 1406.0 & 736.6 & 979.7 \\
\hline
\end{tabular}

\subsection{Method}

\subsubsection{Pettitt test}

Pettitt mutation detection method is Pettitt proposed a nonparametric statistical test method in 1979, this method not only can judge the location of the point mutation in sequence, can determine whether these mutations points in statistically significant.Computational steps are: for the time series of length $\mathrm{n}\left\{\mathrm{X}_{1}, \mathrm{X}_{2}, \ldots, \mathrm{Xn}\right\}$, define statistics:

$$
U_{k}=2 \sum_{i=1}^{K} m_{i}-k(n+1)
$$

Type: $m_{i}$ as the original sequence $\left\{\mathrm{X}_{1}, \mathrm{X}_{2}, \ldots, \mathrm{Xn}\right\}$ in accordance with the corresponding serial number value since the childhood is arranged by $\mathrm{Xi} ; \mathrm{K}=1,2, \ldots$, n.Statistical variable $K=\max \left|U_{k}\right|(1 \leq k \leq n)$;Pettitt critical statistics:

$$
K_{a}=\left[\frac{-\ln \alpha\left(n^{3}+n^{2}\right)}{6}\right]^{1 / 2}
$$

Type in the a significance level.The original hypothesis does not exist for sequence mutation points, if meet acuity $\mathrm{K}$ is considered in the level of significance to detect the mutation point is significant in statistical sense[9-10].

3.2.2 accumulative anomaly analysis

accumulative anomaly is also a kind of commonly used by the trend curve of intutive judgment method. for the sequence $X$, the anomaly is expressed as accumlated a certain time t[11]:

$$
\begin{aligned}
& \overline{x_{t}}=\sum_{i=1}^{n}\left(x_{i}-\bar{x}\right) \quad(t=1,2, \cdots, n) \\
& \bar{x}=\frac{1}{n} \sum_{i=1}^{n} x_{i}
\end{aligned}
$$

3.2.3 Double mass curve analysis

Double mass curve method is based on the slope of the curve cumulative rainfall and the cumulative sediment discharge changes of water and sediment trend analysis by using the method. Basic process is: with two variables $\mathrm{x}$ (rainfall) and $\mathrm{y}$ (sediment discharge), in the $\mathrm{n}$ years of observation period, has the observed value buy $\mathrm{Xi}$ and $\mathrm{Yi}(\mathrm{i}=1,2,3, \ldots, \mathrm{n})$, the variables $\mathrm{Xi}$ and $\mathrm{Yi}$ in chronological sequence respectively calculate the cumulative values, New Year accumulated sequence $X^{\prime}$ and $Y^{\prime}, X^{\prime}$ and $Y^{\prime}$ on the accumulated sequence to do a scatter diagram and fitting regression equation, the equation of slope change unit of rainfall caused by the change of sediment discharge, if the slope turn that human activity changed the watershed underlying surface water and sediment characteristics, so as to confirm the abrupt change point of the rainfall and sediment [12-13].

3.2.4 Slope change ratio of cumulative quantity

slope change ratio of cumulative quantity[14] can be used to the quantitative assessment of rainfall and the contribution of human activities on the watershed sediment yield.Main idea is: this method assumes that the abrupt point linear relation between the two periods and the accumulated sediment discharge of slope YBS and YAS respectively (unit: $\mathrm{m} t / \mathrm{a}$ ); the abrupt point linear relation between the two periods and Cumulative rainfall of slope of YBP respectively and YAP (unit: mm/a), the cumulative slope sediment discharge rate (unit: \%) as follows:

$$
K_{S}=\left(Y_{B S}-Y_{A S}\right) / Y_{B S} \times 100=\left(1-Y_{A S} / Y_{B S}\right) \times 100
$$

the cumulative slope Cumulative rainfall rate (unit: \%) as follows:

$$
K_{P}=\left(Y_{B P}-Y_{A P}\right) / Y_{B P} \times 100=\left(1-Y_{A P} / Y_{B P}\right) \times 100
$$


Rainfall and the contribution rate of human activities on the sediment discharge change $\mathrm{W}_{\mathrm{P}}$ and $\mathrm{W}_{\mathrm{S}}$ (unit: \%) respectively as follows:

$$
\begin{aligned}
& W_{P}=K_{P} / \mathrm{Ks} \times 100=\left(1-Y_{A P} / Y_{B P}\right) /\left(1-Y_{A S} / Y_{B S}\right) \times 100 \\
& W_{S}=1-W_{P}
\end{aligned}
$$

\section{Result analysis}

4.1 annual rainfall/annual sediment mutation analysis

The xiangxi river rainfall and sediment discharge in 1974-2010 hydrological series is tested by Pettitt inspection and accumulative anomaly analysis.the detected result as Fig.1(a), which shows rainfall and sediment are mutated in 1989, rainfall and the sediment mutations is more than the alpha $=0.01$ significant level.Fig.1(b) is the cumulative anomaly distribution performance, annual rainfall in1974-2010 performs decreases after inceeasing first, mutations in year 1989 and pettitt derected mutations piont in the same year ,meanwhile,sediment accumulation analyzed show that the increase with the decrease of the first before and after the division in 1978, obviously mutations of the sediment discharge is 1978 during the period of the year, 1978-2010 sediment discharge accumulation anomaly distribution showed a trend of reduce before the increases, of which 1989 mutation points, same as Pettitt test results,but the abrupt point of the 1978 Pettitt inspection was not detected, this is by examining the characteristics of a point mutation Pettitt can only be determined..

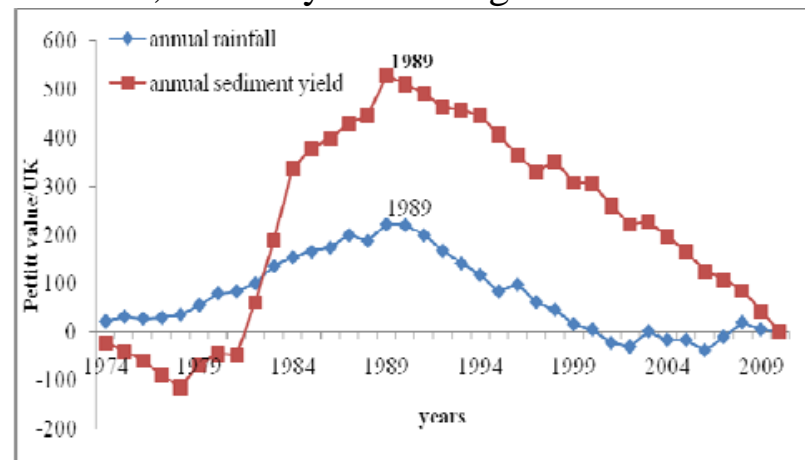

a

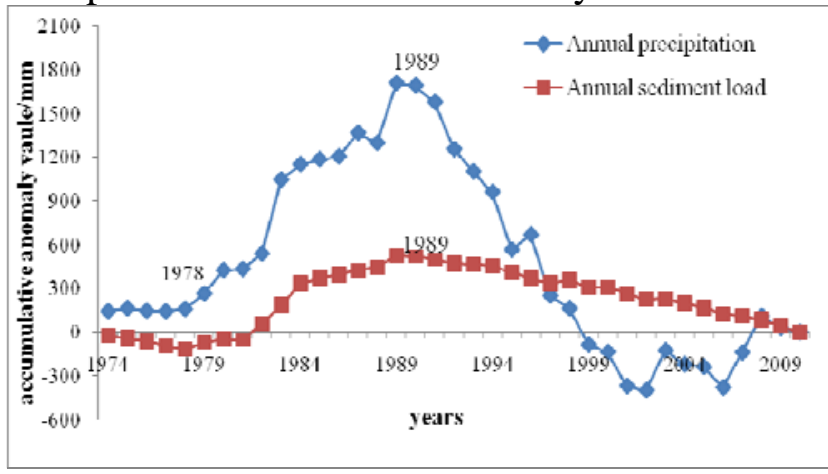

$\mathrm{b}$

Fig.1(a)Pettitt detection of areal precipatation and sediment discharge in Xiangxi river watershed during 1974-2010.( b) Variation of the cumulative precipitation and sediment anomaly of Xiangxi river watershed in 1974-2010.

The trend and inflection point of double-mass curve of precipitation and sediment load will show obvious turning piont universally, namely the accumulation curve slope occurs obvious change, on the basis of whether it is influenced by human activities[14],Fig.2 shows obvious stage characteristics of sediment discharge, its point of each segment and Pettitt inspection and accumulative anomaly judgment of inflection point is consistent,respectively in 1978 and 1989.

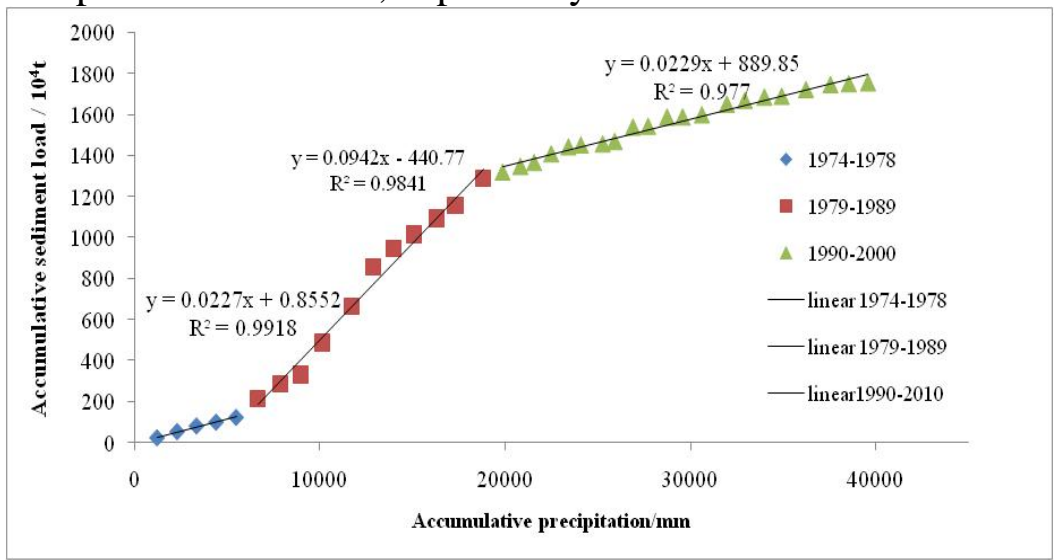

Fig.2 The trend and inflection point of double-mass curve of precipitation and sediment load 
human activity is relatively mil before the 1980s, sediment dischargemainly affected by climate especially precipitation change before 1978 , so will the 1974-1978 as a benchmark.it shows the influence of human activity after 1978, the change of sediment discharge, except under the influence of natural factors such as rainfall and superposition of the effects of human activity.

4.2 Mutation year period of sediment discharge, the relationship between the rainfall and the year

In order to convenient, respectively 1974-1978197-1989 and 1990-2010 is called A, B, C.The AS, BS, CS A, B, C respectively sediment load;AP, BP, CP, respectively. A, B, C during rainfall.

sediment discharge mutation point in 1978, 1989 will be the sediment discharge is divided into three sections: the AS, BS, CS, the relationship between cumulative sediment discharge and the year (Fig. 3 (a)) can be separately fitting out type (8), (9), (10), where $\mathrm{X}$ for years, $\mathrm{Y}$ is cumulative sediment discharge, and represent different periods listed in the table below.

AS: $Y_{A S}=24.29 X_{A S}-47920, R^{2}=0.9917$;

BS: $Y_{B S}=113.32 X_{B S}-224059, R^{2}=0.9781$;

CS: $Y_{C S}=22.695 X_{C S}-43832, R^{2}=0.9872$;

mutation Point in 1989 by rainfall precipitation can be divided into two periods: AP and BP, cumulative rainfall relationship with the year (Fig. 3 (b)) can be separately fitting out type (10), (11), where $\mathrm{X}$ for years, $\mathrm{Y}$ is cumulative rainfall, and represent different periods listed in the table below.

$\mathrm{AP}: Y_{A P}=1179.5 X_{A P}-47920, R^{2}=0.9992$;

BP: $Y_{B P}=113.32 X_{B P}-224059, R^{2}=0.9962$;

Type (8) to (12) of the correlation coefficient $\mathrm{R}$ than significant 0.01 inspection, show that year and accumulated sediment accumulation (rainfall) to establish a relationship.

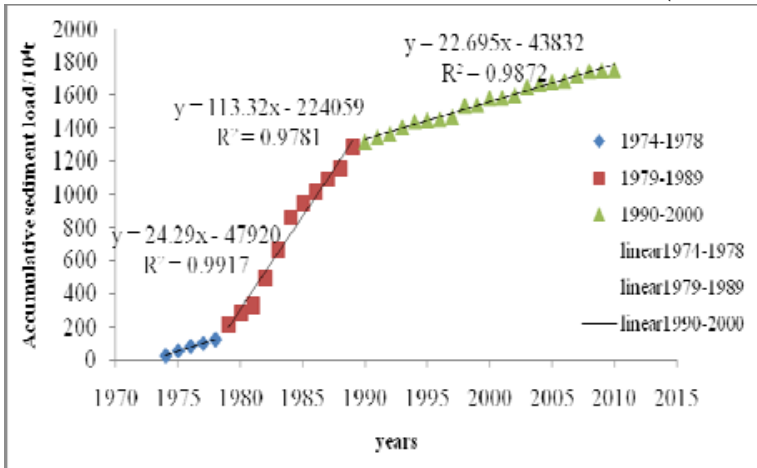

(a)

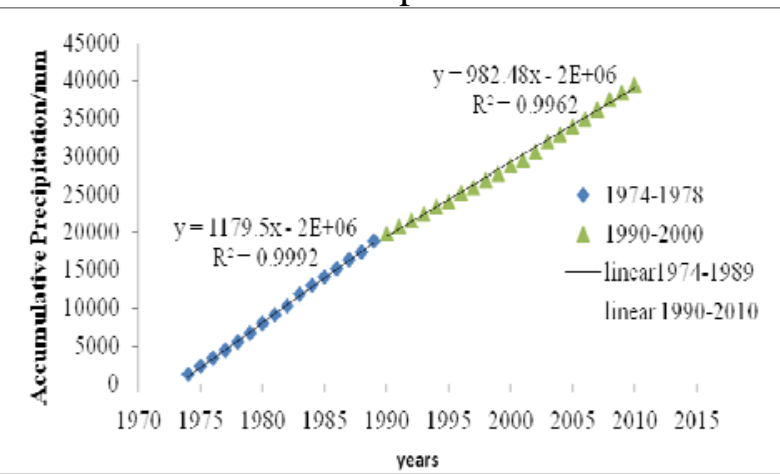

(b)

Fig.3 Relation of years respectively with accumulative sediment and accumenlative precipitation of Xiangxi river watershed

4.3 driving factors of sediment discharge contribution calculation

Table2 shows average annual sediment discharge in 1979-1989 by 242900 t/a in 1974-1978 increases to 1.1332 million t/a, sediment quantity into a $890300 \mathrm{t} / \mathrm{a}$, the change rate of 336.53\% compared to the same period, the cumulative rainfall of the slope is constant, the cumulative rainfall rate of 0 as table 3 shows, compared to A period, sediment discharge increase in B period, mainly is the human activity influence, according to the type (7) computing results: B period is compared with A period, the contribution rate of rainfall on the sediment discharge is 0 , the contribution rate of human activities on the sediment discharge change is $100 \%$.

$\mathrm{C}$ compared with $\mathrm{A}$, sediment discharge rate of $-6.54 \%$, at the same time the rainfall $\mathrm{C}$ compared with A, rainfall rate of $-16.7 \%$, and decreased rainfall has contributed $-255.35 \%$ of sediment discharge decrease, total contribution rate is $100 \%$, the contribution rate of human activities on the sediment discharge change was $155.35 \%$, the increase of human activities on the river sediment discharge, but rain in river sediment reduction is offset by the increase of human activities on the river sediment, makes the river basin in 1990-2010 period to reduce sediment discharge.

Similarly to a 1979-1989, B period as a benchmark, C compared with B, the sediment discharge rate of $-79.97 \%$, at the same time of rainfall compared with $\mathrm{B}, \mathrm{C}$ rainfall rate of- $16.7 \%$, reduce the sediment discharge of rainfall contribution rate is $20.89 \%$, the contribution rate of human activities 
on the sediment discharge change is $79.11 \%$, namely the decrease of sediment discharge caused by decreased rainfall and human activity.

Tab.2 Average annual increment of cumulative sediment and its variation ratios in Xiangxi river watershed

\begin{tabular}{|c|c|c|c|c|c|}
\hline \multirow[b]{2}{*}{ period } & \multirow{2}{*}{$\begin{array}{c}\text { average } \\
\text { annual } \\
\text { sediment } \\
\text { discharge } \\
/\left(10^{4} \mathrm{t}^{-1} \mathrm{a}^{-1}\right)\end{array}$} & \multicolumn{2}{|c|}{ Slope compare with A } & \multicolumn{2}{|c|}{ Slope compare with B } \\
\hline & & $\begin{array}{l}\text { variation } /\left(10^{4} \mathrm{t} \bullet\right. \\
\left.\mathrm{a}^{-1}\right)\end{array}$ & $\begin{array}{c}\text { Change rate } \\
(\%)\end{array}$ & $\begin{array}{l}\text { variation } \\
/\left(10^{4} \mathrm{t} \cdot \mathrm{a}^{-1}\right)\end{array}$ & Change rate $(\%)$ \\
\hline A:1974-1978 & 24.29 & - & - & - & - \\
\hline B:1979-1989 & 113.32 & 89.03 & 366.53 & - & - \\
\hline$C: 1990-2010$ & 22.70 & -1.59 & -6.54 & -90.62 & -79.97 \\
\hline
\end{tabular}

Tab.3 Average annual increment of cumulative precipitation and its variation ratios in Xiangxi river watershed

\begin{tabular}{|c|c|c|c|c|c|}
\hline \multirow[b]{2}{*}{ period } & \multirow{2}{*}{$\begin{array}{l}\text { average } \\
\text { annual } \\
\text { rainfall } \\
\left(\mathrm{mm} \bullet \mathrm{a}^{-1}\right)\end{array}$} & \multicolumn{2}{|c|}{ Slope compare with A } & \multicolumn{2}{|c|}{ Slope compare with B } \\
\hline & & $\begin{array}{l}\text { variation } \\
/\left(\mathrm{mm} \cdot \mathrm{a}^{-1}\right)\end{array}$ & $\begin{array}{c}\text { Change rate } \\
(\%)\end{array}$ & $\begin{array}{l}\text { variation } \\
/\left(\mathrm{mm} \cdot \mathrm{a}^{-1}\right)\end{array}$ & Change rate $(\%)$ \\
\hline A:1974-1978 & 1179.5 & - & - & - & - \\
\hline B:1979-1989 & 1179.5 & 0 & 0 & - & - \\
\hline C:1990-2010 & 982.48 & -197.02 & -16.7 & -197.02 & -16.7 \\
\hline
\end{tabular}

\section{Conclusion}

1) the method of using Pettitt and accumulated anomaly joint detection of xiangxi watershed the abrupt change point of the basin rainfall and precipitation from 1974 to 2010 in 1989,the sediment yield change altered abruptly in 1978 and 1989 , annual precipitation in 1989,respectively. Results compared with the single use Pettitt testing method is more accurate.at the same time, the double mass curve both accumulation rainfall and sediment load have obvious change in 1978 and 1989, further verify the test results.

2) Using the double accumulative curve based on rainfall VS sediment, the whole period was divided into three phases : 1974-1978 , 1979-1989 and 1989-2010; the proportion of contribution of climate and human activities to the sediment yield change were researched by the method of slope change ratio of cumulative quantity. The contribution rates of the human intervention were $100 \%$ during 1979-1989 and 155.35\% during 1990-2010, compared to that during 1974-1978. The contribution rates of the human intervention were $79.11 \%$ during $1990-2010$ compared to that during 1979-1989 .

3) This paper studies the change characteristics of rainfall and sediment in Xiangxi watershed, the quantitative analysis of the contribution rate of human activities and precipitation on the river sediment discharge, but not considered the contribution of other factors of climate factors such as temperature, evaporation, watershed land use and vegetation changes, etc.

\section{Acknowledgements}

This work was financially supported by basic scientific research business expenses of Yangtze river academy of sciences (CKSF2016029/TB).

\section{References}

[1] LI Feng-qing, YE Lin, LIU Rui-qiu, et a1. Investigation on Aquatic Environmental Factors in Xiangxi River W atershed[J]. Ecological Science, 2007, 26(3): 199—207.

[2] CAI Qing-hua, SUN Zhi-yu. Water Environment and Aquatic Ecosystem of Three Gorges Reservoir, China: Progress and Prospects[J]. Journal of Lake Sciences, 2012, 24(2): 169—177. 
[3] SHI De-ming, YANG Yan-sheng. The Countermeasure and Influence on Sediment Sources of Soil Erosion in Three Gorges Reservoir Area[C] // Research Papers of Influence an d Counterm easure of the Th ree Gorges Project on Ecology and Environment. Bering: Sci-ence Press, 1987: $498-521$.

[4]XIANG Li.Study on Ecological water Requirement of Longhe Rivr Watershed[D].Chongqing:

Chongqing University, 2006.

[5]WANG Cheng. Land Use/Cover Change and Soil Erosion Efect Assessment in Longhe Watershed[D]. Chongqing: Southwest University, 2013.

[6] ZHANG Guo-ping. Study on Health Assessment of Longhe River Watershed Ecosystem Based on Ecosystem Service[D]. Chongqing: Chongqing University, 2006.

[7]WANG Hui. Study on Ecological Security Evaluation for Longhe River Watershed[D]. Chongqing: Chongqing University, 2007.

[8] SUN Changan. Study on the relationship between land use and water loss in Xiangxi watershed [D]. Beijing:Beijing Forestry University,2008:22-56.

[9]Pettitt A N. A non-parametric approach to the change point problem [J]. Applied Statistics, 1979, 28(2): 126-135.

[10]Wan Zawish, Wan Zin, Suhaila Jamaludin, et a1. Recentchanges in extreme rainfall events in Peninsular Malaysia: 1971—2005[J]. Theoretical and Applied Climatology, 2010, 99(3/4): $303-314$.

[11]WEI Feng ying. Modem Climatic Sta-tistieal Diagnosis and Prediction Technology[M]. Beijing: Meteorological Press, 2007.

[12]MCRRIAM C F. A Comprehensive Study of Rainfall onthe Susquehanna Valley[J]. Eos, Transactions American Geophysical Union, 1937, 18(2): 471—476.

[13] MU Xing-min, ZHANG Xiu—qin, GAO Peng, et a1. Theory of Double Mass Curves and Its Applications in Hydrology and Meteorology[J]. Journal of China Hydrology, 2010, 30(4): 47-51.

[14]WANG Sui-ji, YAN Yun xia, YAN Ming, et a1. Contributions of Precipitation and Human Activities to the Runof Change of the Huangfuchuan Drainage Basin: Application of Comparative Method of the Slope Chan ng Ratio of Cumulative Quantity[J]. Acta Geographiea Sinica, 2012, 67(3): 388-397. 